\title{
Anti-Homophony Effects in Dakelh (Carrier) Valence Morphology
}

\author{
SUZANNE GESSNER and GUNNAR OLAFUR HANSSON \\ University of Victoria and University of British Columbia
}

\section{Introduction}

In Dakelh (Carrier), as in many other Athapaskan languages, valence prefixes and "inner subject" prefixes interact in a complex pattern involving a combination of consonant deletion and/or fusion and, in certain conditions, what looks like epenthesis. In this paper we investigate this apparent epenthesis effect, which is otherwise unexpected in this environment in Dakelh and is problematic in several aspects (Gessner 2003). We propose that the epenthesis should be understood as an anti-homophony effect (Crosswhite 1999, Blevins 2004a, b) serving to systematically maintain a surface distinction between paradigmatically related forms differing in valence. We demonstrate how the anti-homophony effect is best understood in a diachronic-evolutionary context rather than a synchronicphonological one: "epenthesis" is really the blocking of syncope (as a regular historical sound change). The account constitutes a striking parallel to the explanation of so-called antigemination effects as the result of syncope blocking through homophony avoidance, as proposed by Blevins (2004a, b).

\section{Background \\ 1.1. Language Background}

The focus of this paper is the Lheidli dialect of Dakelh (a.k.a. Carrier), a Northern Athapaskan language of central interior British Columbia. ${ }^{1}$ The Lheidli dialect is not extensively documented (Poser 2001, 2002, Bird 2002, Gessner 2003) and is extremely endangered, with fewer than 10 fluent native speakers. Lheidli is one of 12 Dakelh dialects; the language as a whole is estimated to have 1,000 speakers (Yinka Déné Language Institute 2004). All cited Dakelh data derives from the first author's fieldnotes, except those marked P01 which are from Poser (2001).

\footnotetext{
${ }^{1}$ We sincerely thank speakers Margaret Gagnon, Mary Gouchie and Josephine Paul for providing the Dakelh data. Thanks also to Juliette Blevins, Andrew Garrett and Gary Holland for helpful comments. Fieldwork was supported by SSHRC Doctoral Fellowship 752-2000-2102, a Killam Trust Predoctoral Fellowship and a Jacobs Research Fund grant, all to the first author.
} 


\subsection{Valence Prefixes}

The Athapaskan verb consists of a root, carrying the main lexical meaning, and multiple prefixes serving to mark subject and object agreement, tense, aspect, voice and valency, as well as adverbial and more abstract "thematic" notions. Traditionally, the verb word has been analyzed as consisting of three components: the root (usually called "stem" in the Athapaskanist literature), and two discrete prefixal domains known as the conjunct and disjunct domains (terms attributed to Li 1946). The verb root (typically $/ \mathrm{CV}(\mathrm{C}) /$ ) is immediately preceded by one of a set of voice or valence prefixes traditionally known as "classifiers"; their position is indicated by the shaded box in (1).

(1) Dakelh verb template: ${ }^{2}$

\begin{tabular}{|c|c|c|c|c|c|c|c|c|c|c|c|}
\hline DISJ. \# & Obj & Con & $\mathrm{S}_{\mathrm{O}}$ & $\mathrm{W} / \mathrm{D} / \mathrm{Nq}$ & Cng & Inc & $\mathrm{Neg}$ & Mod/Asp & $\mathrm{S}_{\mathrm{i}}$ & Val & $=\mathrm{ROOT}$ \\
\hline
\end{tabular}

In Dakelh, the phonological forms of the valence prefixes are $\varnothing-$, /do-/, /4-/ and /1-/; an example of each is illustrated in (2).

(2) Valence prefixes ("classifiers") in Dakelh verb forms:

\begin{tabular}{|c|c|c|c|}
\hline$\varnothing-$ & $\mathrm{n} \wedge \mathrm{be}$ & /n \# Ø - Ø = be/ & 's/he is swimming' \\
\hline /d-/ & nadai & $\begin{array}{l}/ \text { na \# Ø - } \mathbf{d}=a i / \\
\text { hab\#3sgS-val=eat }\end{array}$ & 's/he ate' \\
\hline /4-/ & 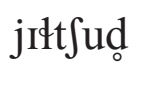 & $\begin{array}{l}\text { /j - I - Ø - } \mathbf{f}=\mathrm{t} \int \mathrm{ud} / \\
\text { obv-asp-3sgS-val=grab }\end{array}$ & ' $\mathrm{s} /$ he is grabbing it' \\
\hline /1-/ & nılg̊ai & $\begin{array}{l}\text { /n \# Ø - l = gaai/ } \\
\text { cur\#3sgS-val=run }\end{array}$ & ' $\mathrm{s} /$ he is running' \\
\hline
\end{tabular}

The / $\mathrm{A}-/$ valence can serve as a transitivizer or causativizer, adding an argument to a verb, while the /d-/ valence marks functions such as the passive, reflexive, reciprocal and iterative, removing an argument from a verb. The /1-/ valence is usually seen as a portmanteau morph, combining the syntactic and semantic properties of the /4-/ and /d-/ prefixes (see, e.g., Young and Morgan 1987, 1992.) ${ }^{3}$

Apart from these productive uses, there are also many instances where the appearance of a valence prefix with a particular verb seems to be idiosyncratic; in those cases, the prefix must be specified in the lexicon as part of that verb's subcategorization. Because of their puzzling nature, valence prefixes are a common

\footnotetext{
${ }^{2} \mathrm{Obj}=$ object agreement; $\mathrm{Con}=$ conative; $\mathrm{S}_{\mathrm{O}}=$ outer subject agreement $(1 \mathrm{p}, 3 \mathrm{dp}) ; \mathrm{W} / \mathrm{D} / \mathrm{Nq}=\mathrm{Wh}-$ class/D-class/N-class absolutive argument qualifier; $\mathrm{Cng}=$ conjugation prefixes marking aspect; Inc $=$ inceptive; Neg = negative; Mod = mode; Asp = aspect; $S_{i}=$ inner subject agreement $(1 / 2 / 3 \mathrm{~s}$, $1 \mathrm{~d}, 2 \mathrm{dp}) ; \mathrm{Val}=$ voice/valency. The symbols ' $\#$ ' and '=' indicate the disjunct-conjunct and prefixroot boundary, respectively. The disjunct domain prefixes are not shown in detail in (1).

${ }^{3}$ Alternatively, /1-/ valence can be interpreted as underlying /do-1-/ with D-Effect (Howren 1971).
} 
topic of investigation in the Athapaskan literature (see Hoijer 1946; Krauss 1969; Kibrik 1993, 1996; Thompson 1996; Hale 1997; Rice 2000a, b; Gessner 2001).

Recall that / $\mathrm{A}-/$ marks transitivity or increased valence (e.g., causativity), while /d./ is typically valence-decreasing (passive, reflexive). This, and the status of /l-/ as being (in some sense) a combination of $/ \mathrm{A}-/$ and $/ \mathrm{d}-/ /$, means that the opposition $/ 1-/: / 4-/$ is parallel to the opposition /do-/ : Ø-, as well as to $\varnothing-: / /-/$, as illustrated in (3). Thus a great number of active vs. passive or causative vs. base form pairs are distinguished solely by a morphological alternation in /A-/ vs. /l-/, as in (3b).

(3) Examples of valence alternations:

a. Ø- $\sim /$-/ alternations:

\begin{tabular}{|c|c|}
\hline Intransitive & Transitive \\
\hline $\mathrm{t}^{\mathrm{h}} \mathrm{et}^{\mathrm{h}} \Lambda \mathrm{n}$ & $\mathrm{j} \Lambda \mathrm{t}^{\mathrm{h}} \varepsilon \mathbf{t t}^{\mathrm{h}} \Lambda \mathrm{n}$ \\
\hline $\mathrm{t}^{\mathrm{h}} \mathrm{e}-\varnothing-\varnothing=\mathrm{t}^{\mathrm{h}} \Lambda \mathrm{n}$ & $\mathrm{j}-\mathrm{t}^{\mathrm{h}} \mathrm{e}-\varnothing-\mathrm{t}=\mathrm{t}^{\mathrm{h}} \Lambda \mathrm{n}$ \\
\hline fut-3sS-val=freeze $\mathrm{I}_{\mathrm{IA}}$ & obv-fut-3sS-val=freeze ${ }_{I A}$ \\
\hline 'It is going to freeze.' & ' $\mathrm{S} / \mathrm{he}$ is going to freeze it' \\
\hline$\Lambda$ tso & j $\Lambda$ Itso \\
\hline$\varnothing-\varnothing=$ tso & $\mathrm{j}-\varnothing-\mathbf{t}=$ tso \\
\hline $3 \mathrm{sS}-\mathrm{val}=\mathrm{cry}_{\mathrm{IA}}$ & obv-3sS-val=cry IA \\
\hline ' $\mathrm{S} /$ he is crying' & ' $\mathrm{S} / \mathrm{he}$ is making him/her cr \\
\hline
\end{tabular}

b. /1-/ /4-/ alternations:

\begin{tabular}{|c|c|}
\hline & Transitive \\
\hline \multicolumn{2}{|l|}{$\frac{\text { Intransitive }}{\mathrm{x}^{\mathrm{w}} \mathrm{en} \Lambda \mathrm{lm} \Lambda 1}$} \\
\hline $\mathrm{x}^{\mathrm{w}} \mathrm{e} \# \mathrm{n}-\varnothing-\mathrm{l}=\mathrm{m} \Lambda \mathrm{l}$ & $\mathrm{x}^{\mathrm{w}} \mathrm{e} \# \mathrm{j}-\mathrm{n}-\varnothing-\mathrm{y}=\mathrm{m} \Lambda \mathrm{l}$ \\
\hline inc\#nq-3sS-val=roll $\mathrm{IA}$ & inc\#obv-nq-3sS-val=roll ${ }_{\mathrm{IA}}$ \\
\hline 'It is rolling' & 'S/he is rolling it' \\
\hline $\mathrm{d} \Lambda \mathrm{n} \Lambda \operatorname{lm} \Lambda \mathrm{t}$ & $\mathrm{j} \Lambda \mathrm{d} \Lambda \mathrm{n} \Lambda \mathrm{Am} \Lambda \mathrm{t}$ \\
\hline d-n-Ø-l=m $=\mathrm{t}$ & j-d $-n-\varnothing-\mathbf{A}=m \wedge \mathrm{t}$ \\
\hline dq-cng-3sS-val=boil ${ }_{\mathrm{IA}}$ & obv-dq-cng-3sS-val=boil $1_{\mathrm{IA}}$ \\
\hline 'It is boiling' & 'S/he is boiling it' \\
\hline
\end{tabular}

\section{Valence-Subject Interaction}

\subsection{Fusion, Deletion, Epenthesis}

The valence prefix is in turn directly preceded by one of the so-called "inner subject" prefixes, marking person and number: $1 \mathrm{Sg} / \mathrm{s}-/, 2 \mathrm{Sg} / \mathrm{in}-/, 1 \mathrm{Du} / \mathrm{id} \Lambda \mathrm{d}-/$, $2 \mathrm{Du} / \mathrm{Pl} / \mathrm{h}-/(3 \mathrm{Sg}$ is $\varnothing-; 1 \mathrm{Pl} / \mathrm{ts}$ '-/ and $3 \mathrm{Du} / \mathrm{Pl} / \mathrm{h}-/$ are the "outer subject" prefixes, located further away from the root). The positions of these two prefix classes in the verb template are highlighted in (4), repeated from above. 
(4) Inner subject and valence prefixes in the Dakelh verb template:

\begin{tabular}{|c|c|c|c|c|c|c|c|c|c|c|c|}
\hline DISJ.\# & Obj & Con & $\mathrm{S}_{\mathrm{O}}$ & W/D/Nq & Cng & Inc & Neg & Mod/Asp & $\mathrm{S}_{\mathrm{i}}$ & Val & $=$ ROOT \\
\hline
\end{tabular}

As shown in (5), the $/ 4-/$ and $/ 1-/$ prefixes interact with the consonant of a preceding subject prefix, if any, by a complex pattern in the Lheidli dialect (Poser 1999); illustrative examples follow in (6).

(5) Interaction of "inner subject" prefixes with valence prefixes /1-/ vs. /1-/:

\begin{tabular}{|c|c|c|c|c|c|}
\hline & $/ \mathrm{s}-/(1 \mathrm{Sg})$ & $/ \mathrm{In}-/(2 \mathrm{Sg})$ & $\varnothing(3 \mathrm{Sg})$ & $/ \mathrm{id}_{\mathrm{o}} \Lambda \mathrm{d}-/(1 \mathrm{Du})$ & $/ \mathrm{h}-/(2 \mathrm{Du} / \mathrm{Pl})$ \\
\hline /A-l & S- & I\$- & A- & $\operatorname{id}_{\circ} \Lambda 1-$ & d- \\
\hline$/ 1-/$ & $\mathbf{\$ \Lambda}-$ & Il- & $1-$ & $\mathrm{id}_{\alpha} \Lambda \mathrm{l}-$ & $\mathbf{\$}-$ \\
\hline
\end{tabular}

(6) Examples of subject-valence interactions in Lheidli Dakelh:

a. /4-/ valence:

\begin{tabular}{|c|c|c|c|}
\hline Prefixes & Transcription & Morpheme Gloss & Gloss \\
\hline /s-1-/ & $\mathrm{d}_{0} \Lambda \mathrm{n} \Lambda \mathrm{sm} \Lambda \mathrm{A}$ & Ø-do-n-s-d=m^t & 'I am boiling it.' \\
\hline & & $3 \mathrm{sO}-$ dq-cng- $1 \mathrm{sS}-\mathrm{val}=$ boil $_{\mathrm{IA}}$ & \\
\hline /In-\$-/ & $\mathrm{d}_{0} \Lambda \mathrm{nI} \mathrm{dm} \Lambda \mathrm{t}$ & Ø-don-In-t=m $=m \wedge$ & 'You ${ }_{\text {sg }}$ are boiling it.' \\
\hline /Ø-৭-/ & $\mathrm{j} \Lambda \mathrm{d} \Lambda \mathrm{n} \Lambda \mathrm{fm} \Lambda \mathrm{q}$ & 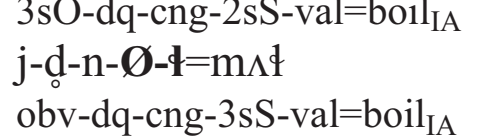 & 'S/he is boiling it.' \\
\hline /idod $\Lambda$ d-1-/ & $\underset{0}{\mathrm{~d}} \Lambda \operatorname{nid} \mathbf{\alpha} \Lambda \operatorname{lm} \Lambda \AA$ & $\begin{array}{l}\text { Ø-do-n-id } \mathbf{d} \mathbf{d}-\mathbf{t}=\mathrm{m} \Lambda \mathrm{t} \\
3 \mathrm{sO}-\mathrm{dq}-\mathrm{cng}-1 \mathrm{dS}-\mathrm{val}=\mathrm{boil}_{\mathrm{IA}}\end{array}$ & 'We $\mathrm{d}_{\mathrm{d}}$ are boiling it.' \\
\hline /h-\$-/ & $\mathrm{d}_{0} \Lambda \mathrm{n} \Lambda \mathrm{dm} \Lambda \AA$ & $\begin{array}{l}\emptyset-\mathrm{d}-\mathbf{n}-\mathbf{h}-\mathbf{-}=\mathrm{m} \Lambda \mathrm{t} \\
3 \mathrm{sO}-\mathrm{dq}-\mathrm{cng}-2 \mathrm{dpS}-\mathrm{val}=\text { boil }_{\mathrm{I}} \mathrm{A}\end{array}$ & 'You ${ }_{\mathrm{dp}}$ are boiling it.' \\
\hline
\end{tabular}

b. /1-/ valence:

\begin{tabular}{|c|c|c|c|}
\hline Prefixes & Transcription & Morpheme Gloss & Gloss \\
\hline /s-1-/ & $\mathrm{n} \Lambda$ łıg̊ai & $\mathrm{n} \# \mathbf{s}-\mathbf{I}=\mathrm{g} a \mathrm{ai}$ & 'I am running.' \\
\hline /In-1-/ & nılg̊ai & $\begin{array}{l}\text { cur\#1sS-val=run }{ }_{\mathrm{IA}} \\
\mathrm{n} \# \mathbf{I n}-\mathbf{l}=\mathrm{g} a \mathrm{i} \\
\text { cur\#2sS-val=run }\end{array}$ & 'You sg are running.' \\
\hline /Ø-1-/ & nılg̊ai & $\begin{array}{l}\text { n\#Ø-l=g̊ai } \\
\text { cur } \# 3 \text { sS-val }=\text { run }_{\text {IA }}\end{array}$ & ' $\mathrm{S} /$ he is running.' \\
\hline /ido $\Lambda$ do-l-/ & niduslg̊ai & $\begin{array}{l}\text { n\#ids d d-l=g̊ai } \\
\text { cur\#1dS-val=run }\end{array}$ & ' $\mathrm{We}_{\mathrm{d}}$ are running.' \\
\hline /h-1-/ & nıłıg̊ai & $\begin{array}{l}\text { n\#h-l=g̊ai } \\
\text { cur\#2dS-val=run }\end{array}$ & 'Youd are running.' \\
\hline
\end{tabular}

Of particular interest is the apparent epenthesis in 1Sg and 2Du/P1 forms with /1-/ valence, which is otherwise anomalous within Lheidli phonology (Gessner 2003). The $1 \mathrm{Sg}$ vs. $3 \mathrm{Sg}$ pairs in (7) give further illustration of the mapping $/ \mathrm{s}-\mathrm{A}-/ \rightarrow\left[1 \Lambda^{-}\right]$. 
(7) Additional examples contrasting $1 \mathrm{Sg}$ and $3 \mathrm{Sg}$ :

\begin{tabular}{|c|c|}
\hline $1 \mathrm{Sg}$ Subject & 3Sg Subject \\
\hline $\begin{array}{l}\mathrm{x}^{\mathrm{w}} \Lambda \text { nawdequnoh } \\
/ \mathrm{x}^{\mathrm{w}} \text {-na\#u-de-s-l=noh/ } \\
\text { inc-hab\#con-thm-1 sS-val=forget } \mathrm{PA} \\
\text { 'I forgot' }\end{array}$ & $\begin{array}{l}\mathrm{x}^{\mathrm{w}} \Lambda \text { nawdelnoh } \\
/ \mathrm{x}^{\mathrm{w}} \text {-na\#tu-de-Ø-l=noh/} \\
\text { inc-hab\#con-thm-3sS-val=forget } \mathrm{PA} \\
\text { 's/he forgot' }\end{array}$ \\
\hline $\begin{array}{l}\text { naded } \Lambda \mathrm{d} \Lambda \mathrm{Z} \\
\text { /na\#\#de-s-l=d } \mathrm{d}_{\mathrm{d}} \Lambda \mathrm{Z} / \\
\text { downtthm-1sS-val=fall } \\
\text { 'I fell down' }\end{array}$ & 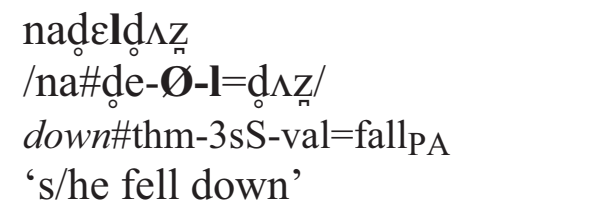 \\
\hline
\end{tabular}

Epenthesis in $1 \mathrm{Sg}$ and $2 \mathrm{Du} / \mathrm{Pl}$ forms with /1-/ valence is a characteristic shared by all dialects in the Southern branch of Dakelh (Poser 1999); in the Nak'albunDzinghubun branch (including the Nak'azdli dialect described by Morice 1932) we find fusion without any concomitant epenthesis:

(8) Epenthesis with /1-/ valence; no corresponding epenthesis with/4-/:

\begin{tabular}{|c|c|c|c|c|}
\hline $\begin{array}{l}1 \mathrm{Sg} \\
2 \mathrm{Du} / \mathrm{P} 1\end{array}$ & $\begin{array}{l}/ \ldots+\mathrm{s}+1+\mathrm{CV}(\mathrm{C}) / \\
/ \ldots+\mathrm{h}+1+\mathrm{CV}(\mathrm{C}) /\end{array}$ & $\begin{array}{l}\rightarrow \\
\rightarrow\end{array}$ & $\begin{array}{c}\text { Lheidli } \\
\ldots \ldots+{ }_{\Lambda} \mathrm{CV}(\mathrm{C}) \\
\ldots \mathrm{A}_{\Lambda} \mathrm{CV}(\mathrm{C})\end{array}$ & $\begin{array}{c}\text { Nak'azdli } \\
\ldots \mathrm{zCV}(\mathrm{C}) \\
\ldots \mathrm{HCV}(\mathrm{C})\end{array}$ \\
\hline $1 \mathrm{Sg}$ & $/ \ldots+\mathrm{s}+\mathrm{A}+\mathrm{CV}(\mathrm{C}) /$ & $\rightarrow$ & $\ldots \mathrm{sCV}(\mathrm{C})$ & $\begin{array}{r}\ldots \mathrm{sCV}(\mathrm{C}) \\
\mathrm{tCV}(\mathrm{C})\end{array}$ \\
\hline 2DuPl & $/ \ldots+\mathrm{h}+\mathrm{A}+\mathrm{CV}(\mathrm{C}) /$ & $\rightarrow$ & $\ldots \operatorname{lCV}(\mathrm{C})$ & $\ldots \mathrm{ACV}(\mathrm{C})$ \\
\hline
\end{tabular}

Epenthesis cannot be a purely prosodically driven phenomenon here, for two reasons. First, in the output form, $[\Lambda]$ is breaking up what would otherwise simply be a biconsonantal cluster (coda + onset); such $\mathrm{AC}$ or $1 \mathrm{C}$ clusters are otherwise not prohibited or avoided in any way at the valence-root boundary, cf. the $2 \mathrm{Sg}$ and $3 \mathrm{Sg}$ forms in (5)-(6) above. Secondly, other triconsonantal SUBJ-VAL-ROOT input sequences are always resolved by fusion of $\mathrm{C} 1$ and $\mathrm{C} 2$, or deletion of $\mathrm{C} 1$ or $\mathrm{C} 2$, without resorting to epenthesis, e.g., $/ \mathrm{s}+\mathrm{H}+\mathrm{C} / \rightarrow[\mathrm{sC}]$ and $/(\mathrm{i}) \mathrm{n}+\mathrm{l}+\mathrm{C} / \rightarrow[(\mathrm{i}) \mathrm{lC}]{ }^{4}$

\subsection{Epenthesis as an Anti-Homophony Effect}

We propose that the apparent epenthesis effect should be understood in relation to the function it plays within the paradigm of morphological oppositions. Were it not for epenthesis, $1 \mathrm{Sg}$ and 2Du/Pl intransitive forms with /1-/ valence would have a surface realization identical to that of the corresponding transitive forms with /4-/ valence. The epenthetic $[\Lambda]$ can be viewed as serving the purpose of systematically maintaining a surface distinction between related verb forms

\footnotetext{
${ }^{4}$ For an Optimality-Theoretic analysis of consonant fusion in similar contexts in a related Northern Athapaskan language, Dené Soun'liné (previously known as Chipewyan), but without any of the epenthesis effects observed in Dakelh, see de Lacy (2002).
} 
differing in valence alone (active vs. passive, causative vs. base). Epenthesis is thus a paradigmatic homophony avoidance effect (cf. Crosswhite 1999; Blevins 2004a, b).

Given the regular strategy used to resolve CCC clusters at the SUBJ-VAL-ROOT boundary, /s-/ and /1-/ should fuse into [s-], and likewise /h-/ and /1-/ should fuse as [1-]. The expected vs. the observed outcomes of subject-valence interactions are outlined schematically in (9), accompanied by relevant examples in (10).

(9) Expected vs. actual outcome in $1 \mathrm{Sg}$ and $2 \mathrm{Du} / \mathrm{Pl}$ with /1-/ valence:

\begin{tabular}{|c|c|c|c|c|}
\hline $\begin{array}{l}\text { 1Sg: } \\
\text { 2Du/Pl. }\end{array}$ & $\begin{array}{l}\text { /-s-1-CV }(\mathrm{C}) / \\
/-\mathrm{h}-1-\mathrm{CV}(\mathrm{C}) /\end{array}$ & $\rightarrow$ & $\begin{array}{l}\text { expected: } \\
* *-s C V(C) \\
* *-4 C V(C)\end{array}$ & $\begin{array}{c}\text { actual: } \\
-\mathrm{A}_{\Lambda} \mathrm{CV}(\mathrm{C}) \\
-\mathrm{A}_{\Lambda} \mathrm{CV}(\mathrm{C})\end{array}$ \\
\hline cf. 1Sg: & /-s-4-CV $(C) /$ & $\rightarrow$ & $-\mathrm{sCV}(\mathrm{C})$ & \\
\hline $2 \mathrm{Du} / \mathrm{Pl}:$ & /-h-4-CV(C)/ & $\rightarrow$ & $-\mathrm{ACV}(\mathrm{C})$ & \\
\hline
\end{tabular}

(10) Examples of $/ 1-/ \sim / 1-/$ valence alternations where ambiguity would result:

a. Transitive (/4-/ valence $)^{5}$

\begin{tabular}{|c|c|}
\hline ISg Subject & 3Sg Subject \\
\hline $\mathrm{n} \wedge \mathrm{n} \wedge \mathrm{s} P \mathrm{i}$ & $\mathrm{n} \wedge \mathrm{n} \Lambda \mathrm{qi}$ \\
\hline$n \# n-s-\mathbf{A}=? i$ & $\mathrm{n} \# \mathrm{n}-\boldsymbol{\varnothing}-\mathbf{A}=\mathrm{Pi}$ \\
\hline thm\#imp-1sS-val=hide $\mathrm{IA}$ & thm\#imp-1sS-val=hide ${ }_{\text {IA }}$ \\
\hline 'I am hiding [object]' & ' $\mathrm{S} /$ he is hiding [object]' \\
\hline
\end{tabular}

b. Reflexive (/1-/ valence)

$\underline{1 S g \text { Subject }}$

3 Sg Subject

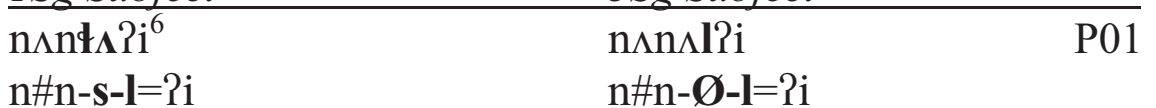

thm\#imp-1sS-val=hide ${ }_{\text {IA }} \quad$ thm\#imp-1sS-val=hide IA $_{\text {IA }}$

'I am hiding myself' ' $\mathrm{S} /$ he is hiding her/himself'

cf. if no epenthesis:

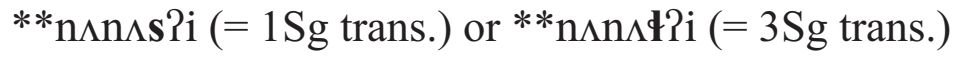

Assuming that the presence of epenthetic $[\Lambda]$ is in fact motivated by a pressure to maintain a valence distinction, an account viewing this as a genuinely synchronic effect (phonological epenthesis triggered by constraints on paradigm homophony avoidance) is still faced with three fundamental problems:

\footnotetext{
${ }^{5}$ These examples are extracted from a sentence with an overt NP object, so no object agreement (/j-/ obviative) is marked on the verb, unlike those $3 \mathrm{Sg}$ transitive forms shown in (2), (3), and (6a). ${ }^{6}$ The actual entry in Poser (2001) is nanlhu' $i$ (= [nanł $\Lambda$ Pi]), glossed as 'I am hiding out'; the [a] is unexpected given that the related forms all have $[\mathrm{n} \Lambda . .$.$] .$
} 
(11) Problems for a synchronic-phonological account:

a. Since fusion of $/ \mathrm{s}-/$ and $/ \mathrm{A}-/$ produces [s], preserving [strident] over [lateral], why would fusion of $/ \mathrm{s}-/$ and $/ 1-/$ yield [1] (plus the epenthetic vowel), apparently preserving [lateral] over [strident]? (Cf. the account of fusion effects in Dené Soun'liné proposed by de Lacy 2002.)

b. Why does /s-1-/ not yield [z-] as it does in the Nak'azdli dialect, cf. (8)? This would preserve the contrast with /s-1-/ $\rightarrow$ [s-] without resorting to epenthesis, while also circumventing the markedness paradox in (a) above.

c. If homophony avoidance is of such great importance in the synchronic grammar, why is a contrast between transitive and intransitive forms not upheld in the 1Du, where we find [ido $\Lambda$-] for both /id $\Lambda$ d-t-/ and /idod-l-/?

The account we propose in the following section provides something of a "Gordian Knot" solution to all of these problems. In our view, $/ \mathrm{A}_{\Lambda}-/$ is simply an unanalyzable portmanteau allomorph from the synchronic point of view, simultaneously an exponent of subject agreement and valence. The presence of $[\Lambda]$ in that allomorph is indeed to be explained as being due to paradigmatic homophony avoidance, but only from a strictly diachronic-historical perspective.

\section{Paradigmatic Homophony Avoidance as a Diachronic Effect}

As argued above, the full details of the homophony avoidance effect seen in subject-valence interactions in Dakelh cannot adequately be explained from a synchronic standpoint. However, we contend that the facts can be accounted for under a diachronic-historical analysis, as outlined in (12).

(12) Central claims:

i. The "epenthetic" vowel in the $\left[\ldots \Lambda_{\Lambda} \mathrm{CV}(\mathrm{C})\right]$ forms is not due to any epenthesis taking place; historically speaking, it was there all along.

ii. The presence of $[\Lambda]$ in these forms is instead due to a failure of syncope, which would otherwise have deleted that vowel (and did so elsewhere).

iii. Homophony avoidance has thus asserted itself by blocking an otherwise regular sound change.

iv. This is a clear parallel to the reinterpretation of "antigemination" effects by Blevins (2004a, b); both are due to homophony avoidance blocking syncope in certain forms.

\section{1. "Epenthesis" as Blocking of Syncope}

Among the valence prefixes as reconstructed for Proto-Athapaskan (henceforth PA) by Krauss (1969), the ancestors of Dakelh /1-/ and /d-/ contained a vowel following the consonant, as shown in (13a). By contrast, $/ 4-/$ did not contain such a vowel (13b), nor did the relevant subject agreement prefixes like $1 \mathrm{Sg} / \mathrm{s}-/(13 \mathrm{c})$ : 
Valence and 1SgSubj prefixes in Proto-Athapaskan (Krauss 1969):
a. $/ 1-/<* 3 \partial-$
b. $\mid \mathrm{A}-/<*$ -
c. $/ \mathrm{s}-/<* \check{s}-$
$/ \mathrm{d}-/<* d \partial-$

Note that both $/ 1-/$ and $/ 4-/$ go back to PA forms containing a voiceless lateral. The generally voiced character of the /1-/ reflex of PA *z-throughout most daughter languages is due to intervocalic voicing. In the vast majority of verb forms, one or more prefixes precede the valence prefix (cf. (1) above), and virtually all of these are reconstructed as having been vowel-final in PA. The effects of intervocalic voicing can also be seen in other prefixes in the conjunct domain, e.g., perfective $[\mathrm{S}(\Lambda)-] \sim[\mathrm{Z}(\Lambda)-]<\mathrm{PA}{ }^{*} \mathrm{~s} \partial$ - (occurring in the position labelled "Cng" in (1)). ${ }^{7}$ In precisely the $1 \mathrm{Sg}$ and $2 \mathrm{Du} / \mathrm{Pl}$ forms at stake here, PA *b- was preceded by $*_{S}$ - or $* h$ - and hence not intervocalic; thus the $\&$ remained voiceless. Subsequent to intervocalic voicing, a regular sound change of syncope deleted the $\partial$ of *z-and *də-, and also in other *Cə- prefixes in similar environments (Krauss 1969).

We suggest that this syncope was blocked in the $1 \mathrm{Sg}$ and $2 \mathrm{Du} / \mathrm{Pl}$ of $*$ 子valence forms, so as not to collapse these with their transitive *t-valence counterparts. We suggest, that is, that the functional pressure of homophony avoidance asserted itself by curtailing a regular sound change. The historical developments of the relevant forms are summarized in (14). On the left is the PA state of affairs, in the middle the result of intervocalic voicing (where applicable), and on the right the current state of affairs after syncope and various cluster simplifications.

(14) Sound changes from Proto-Athapaskan to present-day Dakelh (Lheidli):

a. $1 \mathrm{Sg} *(\ldots V)-\check{S}-\not \partial-C \ldots>*(\ldots V)-\check{s}-\downarrow_{\partial}-C \ldots>(\ldots \mathrm{V})-\mathbf{4} \mathbf{\Lambda}-\mathrm{C} \ldots$ [no syncope]

$2 \mathrm{Sg} *(\ldots)-i n-\mathrm{l}_{\partial}-C \ldots>*(\ldots)-\tilde{l}-\mathrm{l} \partial-C \ldots>(\ldots)-\mathrm{I}-1-\mathrm{C} \ldots$

$3 \mathrm{Sg} *(\ldots V)-\mathrm{d}-C \ldots>*(\ldots V)-l \partial-C \ldots>(\ldots \mathrm{V})-\mathrm{l}-\mathrm{C} \ldots$

$2 \mathrm{Du} *(\ldots V)-h-\mathrm{b}_{\partial}-C \ldots>*(\ldots V)-h-\mathrm{d}_{\partial}-C \ldots>(\ldots \mathrm{V})-\mathbf{4} \mathbf{\Lambda}-\mathrm{C} \ldots$ [no syncope]

b. $1 \mathrm{Sg} *(\ldots V)-\check{s}-t-C \ldots>*(\ldots V)-\check{s}-t-C \ldots>(\ldots V)-\mathrm{S}-\mathrm{C} \ldots$

$2 \mathrm{Sg} *(\ldots)-i n-t-C \ldots>*(\ldots)-\tilde{\imath}-t-C \ldots>(\ldots)-\mathrm{I}-\mathrm{t}-\mathrm{C} \ldots$

$3 \mathrm{Sg} *(\ldots V)-t-C \ldots>*(\ldots V)-t-C \ldots>(\ldots V)-\mathrm{t}-\mathrm{C} \ldots$

$2 \mathrm{Du} *(\ldots V)-h-t-C \ldots>*(\ldots V)-h-t-C \ldots>(\ldots \mathrm{V})-\mathrm{t}-\mathrm{C} \ldots$

Two potential counterarguments should be addressed here. First, it might be argued that the "blocking" merely reflects the phonological conditioning of a sound change, e.g., that syncope was phonotactically restricted so as not to apply in $\mathrm{CC} \_\mathrm{C}$ or $\mathrm{C} \_\mathrm{CC}$ contexts. This interpretation cannot be correct, as the CCC clusters which syncope was prevented from creating, such as $*_{s}-t-C$, were in fact phonotactically permissible in the language. Secondly, it is conceivable that

\footnotetext{
${ }^{7}$ When $/ 1-/<*$ 子 - is initial, its reflex remains voiceless in Dakelh, e.g. Lheidli [ $\left.\mathbf{1} \Lambda j \Lambda l\right]$, Nak'azdli $[\mathrm{dj} \Lambda \mathrm{l}] / \varnothing-\mathrm{l}=\mathrm{j} \Lambda \mathrm{l} /$ 'it (generic) is white', cf. [n $\Lambda \mathrm{lj} \Lambda \mathrm{l}] / \mathrm{n}-\varnothing-\mathrm{l}=\mathrm{j} \Lambda \mathrm{l} /$ 'it (n-class) is white' (Poser 1999).
} 
homophony avoidance served not to block syncope (a sound change), but to trigger the reintroduction of the syncopated vowel based on some other form or forms elsewhere in the paradigm (an analogical change). Unfortunately, however, such forms are nowhere to be found; the only forms where the vowel remained intact (on any cogent interpretation of syncope and its conditioning) are precisely those forms where, on our account, its presence is due to homophony avoidance.

Let us now address the problems listed in (11) above. The diachronic syncope-blocking account provides a simple solution to the dilemma of why, synchronically, $/ \mathrm{s}+\mathrm{t} /$ yields [s] whereas $/ \mathrm{s}+1 /$ yields [ 1$]$ (followed by $[\Lambda]$ ), and why the latter would not instead result, e.g., in [z]. Viewed from the diachronic perspective, the difference is merely one of deleting the first vs. the second member of what was historically a *st cluster, as summarized in (15).

(15) Cluster simplification patterns involving fricative-fricative sequences:

$$
\begin{array}{ll}
\text { a. } & *(\ldots V)-s-t-C(V \ldots)>(\ldots V) s C(V \ldots) \\
& \text { Deletion targets } * \text {, the middle consonant in } \mathrm{C}_{1} \mathrm{C}_{2} \mathrm{C}_{3} \text { cluster. }
\end{array}
$$

b. *(..V)-s-

Deletion targets $*_{s}$, the coda consonant in a $\mathrm{C}_{1} \mathrm{C}_{2}$ cluster.

In the case of $/ 4-/$ valence forms, the valence prefix was a vowelless *-, directly abutting the root-initial consonant, so the cluster was in fact triconsonantal $/ \mathrm{słC} /$. The fact that it is the middle consonant $/ \mathrm{q} /$ that gets deleted is hardly surprising, as it is the one lacking all perceptual cues from $\mathrm{VC}$ and $\mathrm{CV}$ transitions. In /1-/ valence forms, by contrast, the prefix was * $*$ - and the cluster was thus genuinely biconsonantal /st/. Here deletion targets the coda rather than the onset, again the segment with comparatively weaker perceptual cues (Wilson 2001). In sum, the choice is not between "preserving" [strident] over [lateral] or vice versa, as it would be in a synchronic fusion/deletion account, but falls out from the C- vs. $\mathrm{CV}$ - shape the two prefixes had at the time when cluster simplification occurred.

What about 1Du forms, where we find [id $\mathrm{i} l-]$ in /l-/ and /A-/ valence forms alike, in apparent defiance of homophony avoidance? Though the issue cannot be fully addressed here, we suggest that the very form /id $\Lambda$ do-/ of the 1Du prefix is due to a secondary analogical development. Nak'albun dialects of Dakelh, as well as closely related languages, have $1 \mathrm{Du} / \mathrm{id}-/$. As one instantiation of the so-called "D-Effect" (Howren 1971) the /d/ of this /id-/ fuses with a following /4-/ or /1-/ prefix, yielding voiced [1] in both cases and thus neutralizing the valence contrast; the same is true of the second /d/ of the Lheidli /id $\Lambda$ d-/ variant. The original form of the $1 \mathrm{Du}$ prefix may well have been something like *ido-, which would have given rise to a syncope alternation [id $\Lambda-] \sim[\mathrm{i}(\mathrm{d})-]$ depending on the environment (the parentheses indicating fusion with a following C). Lheidli [id $\Lambda$ (d.)-] is a blend of these two alternants, levelling the [id $\Lambda$ ] sequence across all $1 \mathrm{Du}$ forms (cf. a similar development in Pacific Coast Athapaskan mentioned in Krauss 1969). 


\subsection{Syncope Blocking in Other Paradigm Slots}

In addition to $1 \mathrm{Sg}$ and $2 \mathrm{Du} / \mathrm{Pl}$ forms, the same unexpected [ $\left.{ }^{4} \Lambda-\right]$ portmanteau morph shows up in certain $3 \mathrm{Sg}$ forms, where the /1-/ valence is immediately preceded by either perfective /s-/ or negative /s-/ with no intervening vowel. The two forms in (16) both appear to be in the /s/-perfective, contrasting in valence.

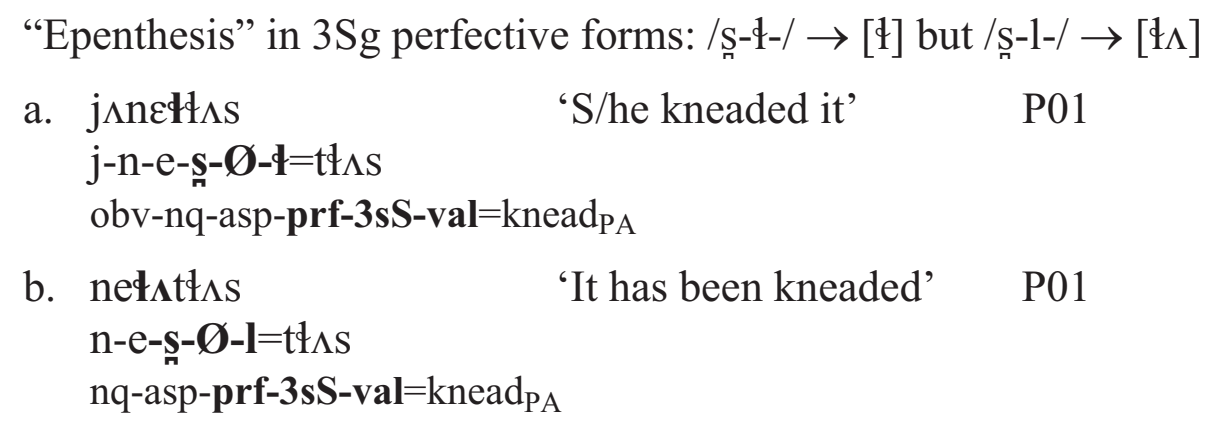

Forms like (16b) likely also arose by syncope blocking in the *to- (>/1-/) valence prefix, motivated by homophony avoidance, though with some further complications. For example, the direct juxtaposition of $/ \mathrm{s}-/$ with the valence prefixes in $3 \mathrm{Sg}$ forms is itself due to syncope, as /s- $/<\mathrm{PA} *$ *a- (Krauss 1969).

Finally, the /d-/ valence prefix ( $<\mathrm{PA} * d \partial-)$ also shows "epenthesis" (i.e., syncope) alternations [d-] [do-] in Lheidli (Gessner 2003). The occurrence of [d $\left.\mathrm{d}_{\Lambda}-\right]$ coincides precisely with those contexts where syncope would have produced an impermissible consonant cluster, which would in turn have triggered deletion of the /d/. This is precisely what happens in the vast majority of related languages, whereas Lheidli and other Southern Dakelh dialects never syncopated such forms in the first place. As forms with /d-/ valence are primarily in opposition to forms with Ø- valence, blocking of syncope (and of the concomitant deletion of /d/) can be explained as a homophony avoidance effect here as well.

\subsection{A Near-Parallel: Antigemination Effects}

Our diachronic account of the mysterious "epenthesis" in Dakelh valence markers constitutes a striking parallel to many of the cases of apparent antigemination effects discussed by Blevins (2004a, b). There too blocking of syncope, previously viewed as a phonological effect (resistance to gemination, e.g. by the OCP), is instead argued to result from paradigmatic homophony avoidance. Syncope would collapse pairs contrasting $\ldots \mathrm{C}_{\mathrm{i}} \mathrm{VC}_{\mathrm{i}} \ldots$ vs. $\ldots \mathrm{C}_{\mathrm{i}} \mathrm{C}_{\mathrm{i}} \ldots$, or else (in languages which actively employ degemination) $\ldots \mathrm{C}_{\mathrm{i}} \mathrm{VC}_{\mathrm{i}} \ldots$ vs. ... $\mathrm{C}_{\mathrm{i}} \ldots$

For example, in Tonkawa (Blevins 2004a) the syncope seen in forms like /picena-o?/ $\rightarrow$ [picno?] 'he cuts it' or /ke-topo-o?/ $\rightarrow$ [ketpo?] 'he cuts me' is blocked when the vowel is flanked by identical consonants, as in /hewawa-o?/ $\rightarrow$ [hewawo?] 'he is dead' or /ke-totopo-o?/ $\rightarrow$ [ketotopo?] 'he cuts me repeatedly'. As Blevins shows, Tonkawa resolves geminates by degemination, such that 
applying syncope in the latter cases would in fact have resulted in **[hewo?], **[ketopo?] (presumably subject to further syncope giving **[ketpo?]).

Tonkawa forms where a potential syncope target is flanked by identical consonants are the result of reduplication (e.g., /hewawa-/ is reduplicated from a base /hewa-/, and /CV-totopo-/ forms contrast with nonreduplicated /CV-topo-/). Syncope, with concomitant degemination, would have completely neutralized such contrasts between reduplicated and non-reduplicated forms of the same verb.

In terms of their diachronic origin, such instances of "antigemination" effects are essentially parallel to the Dakelh developments discussed here. In both cases syncope (as a regular historical sound change) is blocked by considerations of homophony avoidance within paradigms of contrasting forms.

\section{Summary}

The mysterious "epenthesis" found in $1 \mathrm{Sg}$ and $2 \mathrm{Du} / \mathrm{Pl}$ forms with /1-/ valence in Lheidli and other southern dialects of Dakelh finds a coherent explanation in a diachronic account. The synchronic $\mathrm{V} \sim \varnothing$ alternation results not from epenthesis but from syncope blocking, which has served to prevent crucial voice/valence distinctions from being collapsed. Our account explains not only the vowel, but also the voiceless lateral, of the seemingly unexpected [ $\left.{ }^{\Lambda} \Lambda_{-}\right]$morph. Finally, the Dakelh development provides an interesting parallel to "antigemination" effects as reinterpreted by Blevins (2004a, b), since both arise through the blocking of syncope for reasons of paradigmatic homophony avoidance.

\section{References}

Bird, Sonya. 2002. The phonetics and phonology of Lheidli intervocalic consonants. Ph.D. diss., University of Arizona.

Blevins, Juliette. 2004a. Antigemination: Natural or unnatural history. In P. Nowak, C. Yoquelet, and D. Mortensen, eds., Proceedings of BLS 29. Berkeley: Berkeley Linguistics Society.

Blevins, Juliette. 2004b. Evolutionary Phonology. Cambridge: Cambridge University Press.

Crosswhite, Katherine. 1999. Intraparadigmatic homophony avoidance in two dialects of Slavic. UCLA Working Papers in Linguistics 1:48-67.

De Lacy, Paul. 2002. The formal expression of markedness. Ph.D. diss., University of Massachusetts, Amherst.

Gessner, Suzanne. 2001. Linking predicates to information structure: Evidence from Navajo morphological causatives. Ms., University of British Columbia.

Gessner, Suzanne. 2003. The prosodic system of the Dakelh (Carrier) language. Ph.D. diss., University of British Columbia.

Hale, Kenneth. 1997. Remarks on the syntax of the Navajo verb. Parts I, II, III. Ms., MIT and Navajo Community College.

Hoijer, Harry. 1946. The Apachean verb, part III: The classifiers. IJAL 12:51-59. 
Howren, Robert. 1971. A formalization of the Athapaskan 'D-Effect'. IJAL 37: 96-113. Kibrik, Andrej. 1993. Transitivity increase in Athabaskan languages. In B. Comrie and M. Polinsky, eds., Causatives and Transitivity, 47-67. Philadelphia: John Benjamins.

Kibrik, Andrej. 1996. Transitivity decrease in Navajo and Athabaskan. In E. Jelinek, S. Midgette, K. Rice, and L. Saxon, eds., Athabaskan Language Studies. Essays in Honor of Robert W. Young, 259-303. Albuquerque: University of New Mexico Press.

Krauss, Michael E. 1969. On the classification in the Athapascan, Eyak, and the Tlingit verb. (Indiana Univ. Publications in Anthropology and Linguistics, Memoir 24.) Supplement to IJAL 35(4):49-83.

Li, Fang-Kuei. 1946. Chipewyan. In H. Hoijer, ed., Linguistic Structures of Native America, 398-423. New York: Viking Fund.

Morice, Adrien Gabriel. 1932. The Carrier Language. St. Gabriel-Mödling bei Wien, Austria: Verlag der Internationalen Zeitschrift "Anthropos".

Poser, William J. 1999. Features of Carrier dialects. Ms., University of Pennsylvania and Yinka Déné Language Institute.

Poser, William J. 2000. D-Effect related phenomena in Southern Carrier. Paper presented at the Annual Meeting of SSILA, 7 January 2000, Chicago, Illinois.

Poser, William J. 2001. Lheidli Whut'enne Hubughunek (Fort George Carrier Lexicon). 3rd edition. Prince George, BC: Lheidli T'enneh First Nation.

Poser, William J. 2002. A Sketch of the Grammar of the Lheidli Dialect of the Carrier Language. Ms., Lheidli T'enneh First Nation.

Rice, Keren. 2000a. Morpheme Order and Semantic Scope. Cambridge: Cambridge University Press.

Rice, Keren. 2000b. Voice and valency in the Athapaskan family. In R. M. W. Dixon and A. Y. Aikhenvald, eds., Case Studies in Transitivity, 173-235. Cambridge: Cambridge University Press.

Thompson, Chad. 1996. The Na-Dene middle voice: An impersonal source of the D-element. IJAL 62:351-378.

Wilson, Colin. 2001. Consonant cluster neutralisation and targeted constraints. Phonology 18:147-197.

Yinka Déné Language Institute [website]. Ed. William J. Poser. 13 January 2004 (last update). 26 January 2004 (date of access). <http://www.ydli.org>.

Young, Robert and William Morgan. 1987. The Navajo Language: A Grammar and Colloquial Dictionary. Albuquerque: University of New Mexico Press.

Young, Robert, and William Morgan with Sally Midgette. 1992. Analytical Lexicon of Navajo. Albuquerque: University of New Mexico Press.

University of Victoria

PO Box 3045

Victoria, B.C. V8W 3P4

gessner@uvic.ca
University of British Columbia Buchanan E270, 1866 Main Mall

Vancouver, B.C. V6T 1 Z1

ghansson@interchange.ubc.ca 